\title{
Challenges in universal coverage and utilization of insecticide-treated bed nets in migrant plantation workers in Myanmar
}

\author{
Myat H Nyunt ${ }^{*}$, Khin M Aye ${ }^{1}$, Myat P Kyaw ${ }^{1}$, Thar T Kyaw ${ }^{2}$, Thaung Hlaing ${ }^{2}$, Kyaw Oo ${ }^{3}$, Ni N Zaw ${ }^{1}$, Thin T Aye ${ }^{1}$ \\ and Nechi A San ${ }^{1}$
}

\begin{abstract}
Background: High coverage of the bed nets can reduce mortality and morbidity of mosquito-borne diseases including malaria. Although the migrant workers are at high risk of malaria, there are many hidden challenges in universal coverage and utilization of the insecticide-treated nets (ITNs) in this populations.

Methods: Cross sectional study was conducted in 170 migrant workers in palm oil plantation sites in Tanintharyi Region and 175 in rubber plantation sites in Mon State. A multistage stratified cluster sampling was applied to select the participants. During household visit, face-to-face interviews using structured pre-coded, pre tested questionnaires and direct observation on installation of the bed nets was conducted. Two focus group discussions in each site were done by sample stratified purposive sampling method mainly focused on effective utilization of bed nets.
\end{abstract}

Results: Among them, 332 (96.2\%) had a bed net and 284 (82.3\%) had an ITN, while 204 (59.1\%) had unused extranets. Among the ITNs users, 28.9\% reported problems including insecticide smell (56.9\%), dizziness (20.2\%), headache (12.8\%) and itchiness (9.2\%). More than 75\% received ITNs from health authorities and NGOs free-of-charge. More than 70\% wanted to buy a net but they were unaffordable for $64 \%$ of them. On observation, only five families could show no bed net, but 80\% showed 1-3 ITNs. Consistent utilization in all seasons was noted in 189 (53.1\%), that was higher in palm oil plantation than rubber plantation workers $(p=0.0001)$ due to the nature of the work at night. Perceived malaria risk was also significantly higher ITNs consistent users than non-users $(p=0.0004)$ and better willingness to buy an ITN by themselves $(p=0.0005)$. They said that effectiveness of the ITNs was reduced after 6 months and 2-3 times washing. They wished to receive more durable smooth nets with small holes in lace. Misuses of the ITNs such as use the nets for animals and fishing, were also noted.

Conclusion: There should be efforts to improve effective utilization of ITNs by continuous mass free distribution, durability monitoring, surveillance of insecticide resistance of the vector and behaviour change interventions in migrant plantation workers.

Keywords: Malaria, ITN, LLIN, Migrant worker, Myanmar

\section{Background}

The goal established by the Member States at the World Health Assembly and the Roll Back Malaria (RBM) Partnership is to reduce malaria mortality and morbidity recorded in 2000 by $50 \%$ or more by the end of 2010 and by $75 \%$ or more by 2015 [1]. To reach this target, policy maker in endemic countries have to use effective strategies

\footnotetext{
* Correspondence: drmhnyunt@gmail.com

${ }^{1}$ Department of Medical Research (Lower Myanmar), Yangon, Republic of the Union of Myanmar

Full list of author information is available at the end of the article
}

for mosquito control measures including supplying all persons at risk of malaria with insecticide-treated nets (ITNs) or indoor residual spraying [2,3]. High population coverage of the bed nets and effective treatment programmes may reduce the mortality and morbidity of malaria and other mosquito borne diseases up to $50 \%$ in the areas of intense perennial malaria transmission [3]. The World Health Organization (WHO) has recommended that universal coverage with long-lasting insecticidal nets (LLINs) should be achieved and maintained. In 2008, total 
58 countries adopted the WHO recommendation to supply LLINs for all age groups at risk for malaria. This figure has represented an increase of 13 countries since 2007 [4].

One study suggested that free distribution of ITNs could save many more lives than cost-sharing programmes [5]. In 2006-2008, nearly 140 million LLINs were delivered to high burden countries in the African Region. However, it was noted that household ITN/LLINs ownership decreased by $13 \%$ and $37 \%$ after 24 and 36 months of mass distribution respectively indicating that routine distribution programme is important to maintain long-term coverage. WHO recommended routine monitoring of the durability of LLINs and the longevity of the insecticide to assess the requirements for ITNs maintenance [6].

There are many studies world-wide that found huge discrepancy between ownership versus use of ITNs. Studies quantified this difference as 95\% vs 59\% (Kenya) [7], $70 \%$ vs $53.1 \%$ (Nigeria) [8] and 90\% vs 77\% (Tanzania) [9] indicating household ownership was not reflected the utilization of the bed net.

In Myanmar, number of ITNs distributed increased year by year starting from 2001 [4]. Malaria risk areas were prioritized for either free mass distribution of LLIN or treatment of the existing bed nets. In 2011, a total of 800,000 LLINs were distributed and 1,062,723 existing nets were treated. Similarly, the total numbers of $1,450,978$ LLINs were distributed and 1,829,631 existing bed nets were treated in 2012 in malaria endemic areas [10]. These activities covered $5,627,445$ populations in malaria high risk areas. The use of ITNs was thought to be appropriate for undeveloped and remote areas of the country where malaria control was difficult [11]. Challenges with ITNs still remain for replenishment of worn out nets, less efficacy and durability and abuse of nets especially in fishing areas [12]. Myanmar Artemisinin Resistance Containment (MARC) activities have been prepared and mass distribution of LLINs has been started since 2010, mainly focusing on migrant workers. Most of the migrant workers are non-immune and more vulnerable to malaria than local residents. Socioeconomic, personal, occupational and provisional factors influence the utilization of ITNs in migrant plantation workers [13] (Figure 1).

However, there is no documented study on coverage and utilization of ITNs in Myanmar migrant workers. To support the Myanmar Artemisinin Resistance Containment measures, the exploratory study on knowledge, distribution and utilization of ITNs in migrant plantation workers in Myanmar is cardinal.

\section{Methods}

\section{Areas of study}

This cross sectional descriptive study was carried out in Mon State and Tanintharyi Region in Myanmar. Mon State has a lot of rubber plantation sites where many

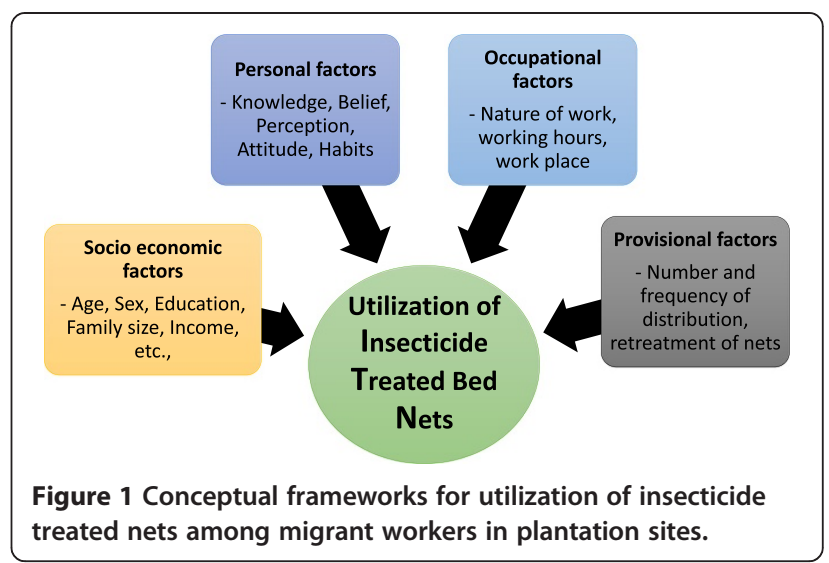

migrant workers are employed and also has high morbidity of malaria. Similarly, many migrant workers from different parts of the country are employed in palm oil plantation sites in Kawthaung District, which has high malaria mortality and morbidity. In these sites, LLINs have been distributed by NGOs and the National Malaria Control Programme. Mass distribution of the LLINs has been distributed by the MARC Programme, in these study sites six months before conducting the survey [14].

\section{Participants in the study}

Only adult migrant plantation workers were selected for the study. A migrant worker was defined as "a person who moves, but stays in one place for more than one month [15] with a view to being employed otherwise than on his own account".

\section{Sample size}

Utilization of the ITNs in all seasons was defined as sustainable use in this study. The sustainable use of ITNs among migrant workers had been found to be $10 \%$ in preliminary study in 2010 . Therefore, assuming the sustainable use of ITNs among migrant population was $10 \%, 5 \%$ precision and $95 \%$ confident interval, nonresponse rate $5 \%(0.95)$, the required sample size was 146. To be representative, sample size was assumed to 160. It was multiplied by a design effect of two for multistage sampling [16]. Therefore, the sample size was 320. At least 160 respondents were selected from each of the study sites because each site has relatively the same population size in villages.

\section{Sampling procedure}

A multistage stratified cluster sampling technique was used. Small villages with adult migrant population less than 60 were excluded to get comparable samples in both sites. Villages where migrant plantation workers were living, were screened and a total of 23 villages in Mon State and 20 villages in Tanintharyi Region were 
listed. From these, four villages were randomly selected. The list of adult migrant subjects was recorded in each of the villages. From these persons, systematic sampling procedures were applied. Sampling interval was calculated as total number of adult migrant subjects divided by 40 . By adding sampling interval to the last respondents starting from the first persons, the study population was formulated. For example, if the migrant population was 80 in a village, sampling interval would be 2 , and every $2^{\text {nd }}$ migrant workers in the list was selected. In this way, 40 respondents from each village i.e. 160 from each of the study sites were included in the study.

Data were collected by face-to-face interviews during household surveys (HHS) using pre-coded questionnaires and focus group discussions (FGD). The questionnaire was designed to collect information on population characteristics, education status, family size, net ownership, knowledge about mosquito nets, and source of nets, bed net utilization, total family members sleeping under nets, presence of unused nets in households and problems while using the net. There are three seasons, (summer, monsoon and winter) in Myanmar and its effect on bed net usage pattern was also assessed. Interviews were conducted by trained interviewers in the local languages using questionnaires adapted and modified from the WHO Malaria Indicator Survey (MIS) tools [17].
The questionnaire was pre-tested and finalized before the study. Moreover, observation of net installation was done in every respondent's household visit. Focus group discussions (FGD) were done at two places in each study site by stratified purposive sampling method. Group members were selected from rubber and palm oil plantation workers and their wives to obtain in depth information on effective utilization of bed nets in their population. Discussion guidelines were formulated as a series of openended questions.

\section{Data management}

Data collected during the survey were checked and entered using Epi Info version 7. Analysis was performed using SPSS version 16. For univariate analysis, frequencies and proportions were calculated for household ownership and utilization of any net and ITNs, and cross-tabulated with background demographic characteristics of the households. Pearson's Chi squared test was used to determine association with a P-value of $<0.05$ accepted as significant. Fisher's exact test was calculated for borderline significance and for cells with expected count less than five.

\section{Ethical consideration}

All respondents were clearly informed on nature and purpose of the study, privacy question, benefits, and the

Table 1 Demographic characteristics of the participants

\begin{tabular}{|c|c|c|c|c|c|c|c|}
\hline \multirow[t]{2}{*}{ Category } & \multirow[t]{2}{*}{ Description } & \multicolumn{2}{|c|}{ Mon State } & \multicolumn{2}{|c|}{ Tanintharyi region } & \multicolumn{2}{|c|}{ Both sites } \\
\hline & & Number & Percent & Number & Percent & Number & percent \\
\hline \multirow[t]{4}{*}{ Age group } & 13-24 years & 25 & 7.2 & 45 & 13.0 & 70 & 20.3 \\
\hline & 25-34 years & 57 & 16.5 & 57 & 16.5 & 114 & 33.0 \\
\hline & $35-44$ years & 38 & 11.0 & 37 & 10.7 & 75 & 21.7 \\
\hline & $>45$ years & 50 & 14.5 & 36 & 10.4 & 86 & 24.9 \\
\hline \multirow[t]{2}{*}{ Sex } & male & 74 & 21.4 & 67 & 19.4 & 141 & 40.9 \\
\hline & female & 96 & 27.8 & 108 & 31.3 & 204 & 59.1 \\
\hline \multirow[t]{4}{*}{ Education status } & No formal education & 40 & 11.6 & 34 & 9.9 & 74 & 21.4 \\
\hline & Primary school level & 79 & 22.9 & 91 & 26.4 & 170 & 49.3 \\
\hline & Middle and high school level & 50 & 14.5 & 47 & 13.6 & 97 & 28.1 \\
\hline & Graduate & 1 & 0.3 & 3 & 0.9 & 4 & 1.2 \\
\hline \multirow[t]{3}{*}{ Family members } & 1 to 3 & 77 & 22.3 & 82 & 23.8 & 159 & 46.1 \\
\hline & 4 to 6 & 78 & 22.6 & 75 & 21.7 & 153 & 44.3 \\
\hline & $>6$ & 35 & 10.1 & 33 & 9.6 & 68 & 19.7 \\
\hline \multirow[t]{5}{*}{ Family income per month (USD) } & $<50$ & 48 & 13.9 & 9 & 2.6 & 57 & 16.5 \\
\hline & $50-79$ & 49 & 14.2 & 28 & 8.1 & 77 & 22.3 \\
\hline & $80-99$ & 27 & 7.8 & 32 & 9.3 & 59 & 17.1 \\
\hline & $100-150$ & 41 & 11.9 & 43 & 12.5 & 84 & 24.3 \\
\hline & $>150$ & 5 & 1.4 & 63 & 18.3 & 68 & 19.7 \\
\hline \multirow[t]{2}{*}{ Perceived risk on malaria } & Yes & 135 & 39.1 & 128 & 37.1 & 263 & 76.2 \\
\hline & No & 35 & 10.1 & 47 & 13.6 & 82 & 23.8 \\
\hline
\end{tabular}


right to refuse to participate or to withdrawal from the study and confidential handling of the data. Participation in this project was entirely voluntary. The interview was done non-working hours not to interference the participants' work. This project was obtained ethical clearance from the ethical committee of the Department of Medical Research (Lower Myanmar) (IERC_3/2010_21).

\section{Results}

\section{Baseline demographic information}

A total of 345 migrant plantation workers from both sites (170 in palm oil plantation sites in Tanintharyi Region and 175 in rubber plantation sites in Mon State) were included in this study. They were migrated from different parts of the country. People of working age (25-45 years) were the major respondents $(54.78 \%, 189 / 345)$. Baseline demographic data were shown in Table 1.

\section{Bed net ownership and utilization pattern}

Although 13 (3.8\%) respondents had no bed net at all, only $15 \%(52 / 345)$ had no ITNs and $27 \%(94 / 345)$ had no untreated bed net in their household. Frequent washing (more than 12 times per year) was noted in 12.6\%. More than half reported going to bed early $9 \mathrm{pm}$. The different seasons may influence the bed net utilization pattern, it was assessed in this study. More than $80 \%$ used bed nets in all seasons regularly but some never use the nets in summer. The main reason for utilization of ITNs was to prevent mosquito bites. Ownership and utilization of the bed nets are shown in Table 2.

\section{Reasons for non-utilization of ITNs}

A total of $31.8 \%(110 / 345)$ said that they had to work at night and this factor was a major reason for non-utilization of ITNs during the whole night. Number of working hours varied among migrant workers $(5.8 \pm 2.4$, mean $\pm \mathrm{SD})$ in rubber plantation sites at Mon State. Reasons for nonutilization of the ITNs were shown in Figure 2.

More than half, 59.1\% (204/345) reported that they had unused nets and 33\% had 1-2 unused extranets. Among the ITNs users, 100 (28.9\%) reported problems while using ITNs, such as insecticide smell 62 (56.9\%), dizziness 22 (20.2\%), headache 14 (12.8\%), itchiness 10 (9.2\%) and difficulty in breathing 1 (0.9\%).

Upon direct observation of the nets installed inside their homes, only five families could not show a bed net (ITN/LLIN or untreated net), but $80 \%$ showed one to three bed nets in the household. Distribution of the ITNs and their willingness to buy an ITN was shown in Table 3.

\section{Source of information on ITNs}

Regarding the source of information on ITNs, health personnel were the major informers to the migrant workers
Table 2 Ownership versus utilization of the bed nets

\begin{tabular}{|c|c|c|c|}
\hline Category & Description & Number & $\%$ of total \\
\hline \multirow[t]{3}{*}{ ITN/LLIN ownership } & 0 net & 52 & 15.1 \\
\hline & 1 to 3 nets & 273 & 79.1 \\
\hline & 4 to 6 nets & 20 & 5.8 \\
\hline \multirow{4}{*}{$\begin{array}{l}\text { Non ITN (untreated } \\
\text { bed net) ownership }\end{array}$} & 0 net & 94 & 27.2 \\
\hline & 1 to 3 nets & 243 & 70.4 \\
\hline & 4 to 6 nets & 7 & 2.0 \\
\hline & $>6$ nets & 1 & 0.3 \\
\hline \multirow[t]{5}{*}{ Washing of ITN/LLIN } & no history of washing & 146 & 42.3 \\
\hline & 1 to 3 per year & 61 & 17.7 \\
\hline & 4 to 6 per year & 45 & 13.0 \\
\hline & 7 to 12 per year & 49 & 14.2 \\
\hline & $>12$ per year & 44 & 12.7 \\
\hline \multirow[t]{4}{*}{ Time to go bed } & Before 9 hour & 202 & 58.5 \\
\hline & 9 to 11 hour & 129 & 37.4 \\
\hline & After 11 hour & 5 & 1.4 \\
\hline & Irregular & 9 & 2.6 \\
\hline \multirow{8}{*}{$\begin{array}{l}\text { Utilization pattern } \\
\text { of different seasons }\end{array}$} & Monsoon only & 3 & 0.9 \\
\hline & $\begin{array}{l}\text { Monsoon and winter } \\
\text { seasons only }\end{array}$ & 12 & 3.4 \\
\hline & winter season only & 2 & 0.6 \\
\hline & All seasons & 281 & 81.4 \\
\hline & When the weather is cold & 11 & 3.2 \\
\hline & $\begin{array}{l}\text { When the mosquitoes } \\
\text { are common }\end{array}$ & 13 & 3.8 \\
\hline & Never & 13 & 3.8 \\
\hline & Others & 10 & 2.9 \\
\hline \multirow[t]{3}{*}{ Reason for utilization } & To prevent weather & 22 & 6.38 \\
\hline & To prevent mosquito bites & 313 & 90.7 \\
\hline & Others & 77 & 22.3 \\
\hline
\end{tabular}

$(45.8 \%, 174 / 380)$ followed by community leaders $(17.6 \%$, $67 / 380)$ and, friend and family $(16.8 \%, 39 / 380)$. It was noted that mass media including television, radio and newspapers have little role in information channels among these migrant workers.

\section{Consistent utilization of ITNs}

Although ITN utilization was noted in most of the households, consistent utilization was noted in 53.1\% (189/145). Consistent utilization of the ITNs was higher in palm oil plantation than rubber plantation workers $\left(x^{2}=94.25, p=0.0001\right)$. This was mainly due to the nature of the work at night among rubber plantation workers. Perceived malaria risk was also significantly higher in consistent ITN users than non-users $\left(x^{2}=12.52, p=0.0004\right)$. Consistent ITN users showed better willingness to buy an 
ITN than non-users $\left(\chi^{2}=12.24, p=0.0005\right)$. But consistent ITN users were less affordable to buy an ITN than non-user $\left(x^{2}=26.37, p=0.0001\right)$.

\section{Qualitative findings on utilization of ITNs}

One of the 21-year old migrant women commented on distributed ITNs as

"I wish to receive the retreatment materials so that we can use ITNs consistently. It should be mentioned how to treat or soak the bed net with insecticide".

\section{A 50-year old migrant woman said}

"I don't know that is ITN. I don't like it because it is too rough in texture with big pits. It looks like the nets used for animals such as buffalos and cows in my native town. Some of villagers use it to catch up fish".

36-year old migrant women also said

"I prefer CYC (Cotton 2-ply) bed net because these ITNs are not wind proof and cause dizziness, insecticide smell, and difficulty in breathing. So, ITNs were not currently used".

Another 30-year old migrant rubber plantation worker mentioned how to prevent the mosquito bites as
"I used to collect the milk from rubber plants the whole night. The ITN distributed is almost useless for me. So, I use mosquito coils on the ladder, long clothes as protective wearing and apply repellent to prevent mosquito bites".

One of the 35-year old respondent said

"The distributed ITN is not long lasting, because it was easily damaged after a few months. Its effectiveness is reduced after 2-3 time washing and now mosquitoes can rest on the net like non-ITN".

A 50-year old migrant worker also expressed his experience as follows:

"Some men sleep outside of the bed net because they are not familiar with the bed net as it causes difficulty in breathing. So they fear to sleep inside a bed net and feel hot. Sometimes, a few men drink heavily and cannot control themselves and sleep outside the net".

\section{Discussion}

Indoor residual spraying (IRS) and insecticide-treated bed net (ITN) remain the frontline interventions for malaria vector control [18]. However, there are many factors contributing to the universal coverage and effective utilization of ITNs. A meta-analysis of household surveys done in Nigeria on net utilization and ownership found a

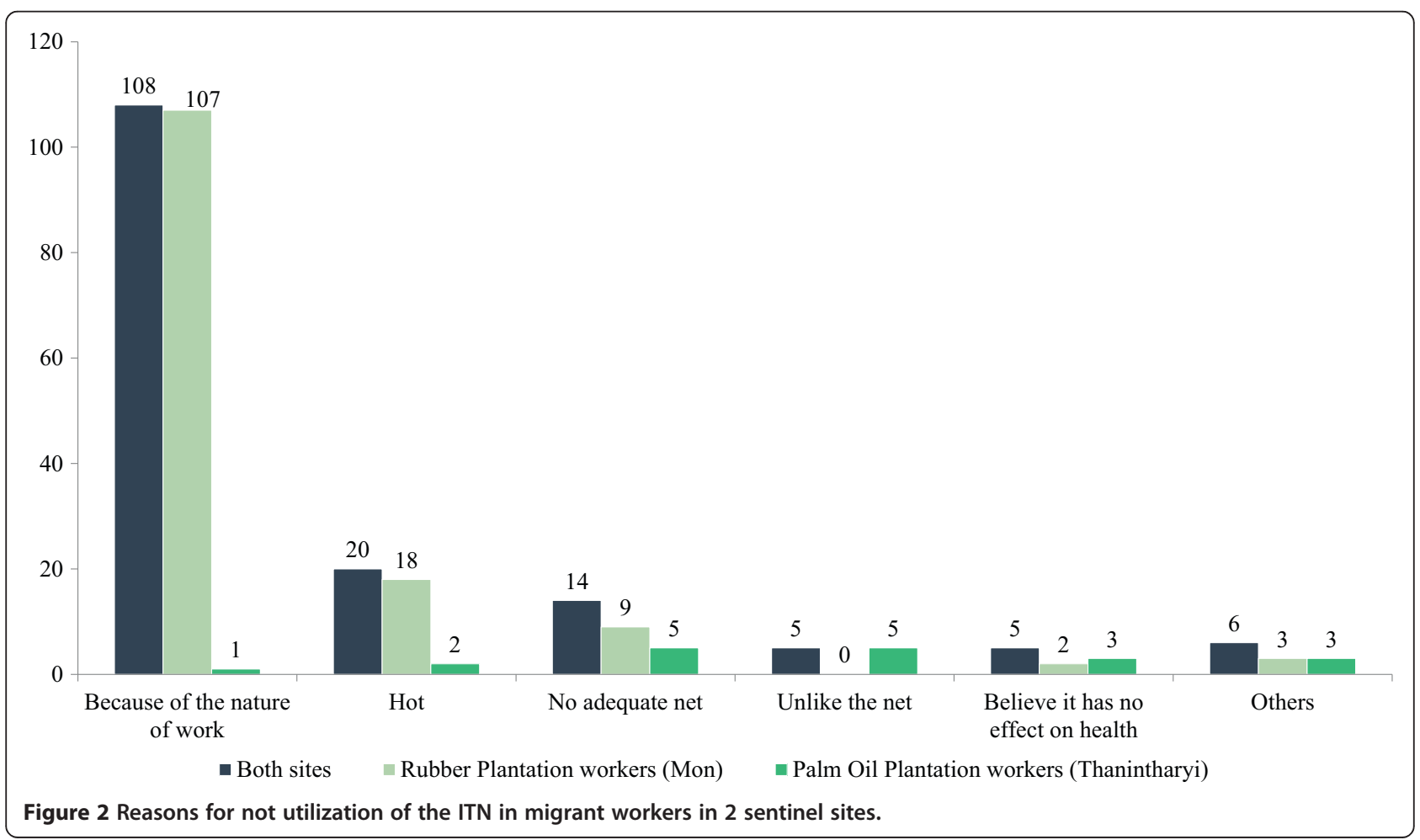


Table 3 Source and distribution of ITN and willingness to buy an ITN

\begin{tabular}{|c|c|c|c|}
\hline Category & Description & Number & Percent \\
\hline \multirow[t]{4}{*}{ Source of ITNs } & Buy from the market & 3 & 0.9 \\
\hline & Local health authorities & 203 & 58.8 \\
\hline & NGOs & 65 & 18.8 \\
\hline & Other & 22 & 6.4 \\
\hline \multirow[t]{2}{*}{ Charges for ITNs } & Received free of charge & 288 & 83.5 \\
\hline & Bought & 5 & 1.4 \\
\hline \multirow[t]{2}{*}{ Affordable to buy ITN } & Yes & 124 & 35.9 \\
\hline & No & 221 & 64.1 \\
\hline \multirow[t]{2}{*}{ Like to buy ITN } & Yes & 256 & 74.2 \\
\hline & No & 89 & 25.8 \\
\hline \multirow{4}{*}{$\begin{array}{l}\text { Number receiving ITN } \\
\text { during free distribution }\end{array}$} & Not received & 51 & 14.8 \\
\hline & 1 time & 224 & 64.9 \\
\hline & 2 times & 45 & 13.0 \\
\hline & More than 3 times & 25 & 7.2 \\
\hline \multirow[t]{4}{*}{ No. of ITN received } & No nets & 51 & 14.8 \\
\hline & 1 net & 121 & 35.0 \\
\hline & 2 nets & 103 & 29.9 \\
\hline & More than 3 nets & 70 & 20.3 \\
\hline \multirow{2}{*}{$\begin{array}{l}\text { Methods or materials } \\
\text { for retreatment }\end{array}$} & Yes & 31 & 8.7 \\
\hline & No & 313 & 87.9 \\
\hline \multirow{4}{*}{$\begin{array}{l}\text { Number of bed net } \\
\text { observed in household }\end{array}$} & No net & 5 & 1.5 \\
\hline & 1 to 3 nets & 274 & 80.1 \\
\hline & 3 to 6 nets & 62 & 18.1 \\
\hline & $>6$ nets & 1 & 0.3 \\
\hline \multirow{2}{*}{$\begin{array}{l}\text { History of fever } \\
\text { within } 2 \text { weeks }\end{array}$} & Yes & 39 & 11.3 \\
\hline & No & 306 & 88.7 \\
\hline
\end{tabular}

wide gap between bed net ownership and utilization [19]. Moreover, utilization varied with seasons of the year. While 99\% of the net recipients were found to use the nets during rainy season, only $20 \%$ was noted during the dry season [20]. Socio-demographic characteristics like age, education, size of household, and ethnicity were also found to influence the use of bed nets [21].

Free and mass distributions of the ITNs were done in both sentinel sites as one of the activities of the MARC Programme. However, sometimes migrant workers cannot use the ITN for the whole night because of the nature of their work. This was obviously noted in rubber plantation sites that need to do their work at night. Most of the ITN users used nets all seasons but some of them slept outside of the bed net because of the hot weather and their bad habits.

Most of migrant workers had heard of ITN only after free distribution. Therefore, the source of information on ITNs was mainly from health personnel, friends and family, and community leaders. Their low education level and lack of adequate facilities lead to difficulty in health education through mass media such as video, FM radio channel, TV programme and press media.

Free distribution was found as one of the major factors causing utilization of ITN in migrant workers. It found that $15 \%$ had no ITN and $27 \%$ had no untreated bed net. But consistent utilization was noted in just $53 \%$ of the respondents because of the nature of work and other behaviours.

Challenges with ITNs still remaining include replenishment of worn out nets, unknown efficacy and durability, and abuse of nets e.g. in fishing areas [12,22]. Misuses of the ITN, such as use to catch fish and use of nets for animals were also noted (Figure 3). Some of them also complain that after a few months of using the ITN, mosquito could adhere the net. This may be due to many factors [23,24] including insecticide resistant mosquitoes, poor quality of the nets, improper installation, frequent washing and drying in direct sunlight. It is important to exclude the insecticide resistant mosquitoes and find out the major factors causing the low effectiveness of the ITNs.

\section{Conclusion}

Universal coverage remains the goal for all people at risk of malaria especially in migrant plantation workers. Free distribution of the ITN/LLINs is crucial to the success of maintaining universal coverage of bed nets in Myanmar. To further improve coverage and effective utilization of ITN/LLINs among migrant workers, regularly updated, interactive, comprehensive national advocacy, IEC/BCC activities, and operations research feeding into and provid-

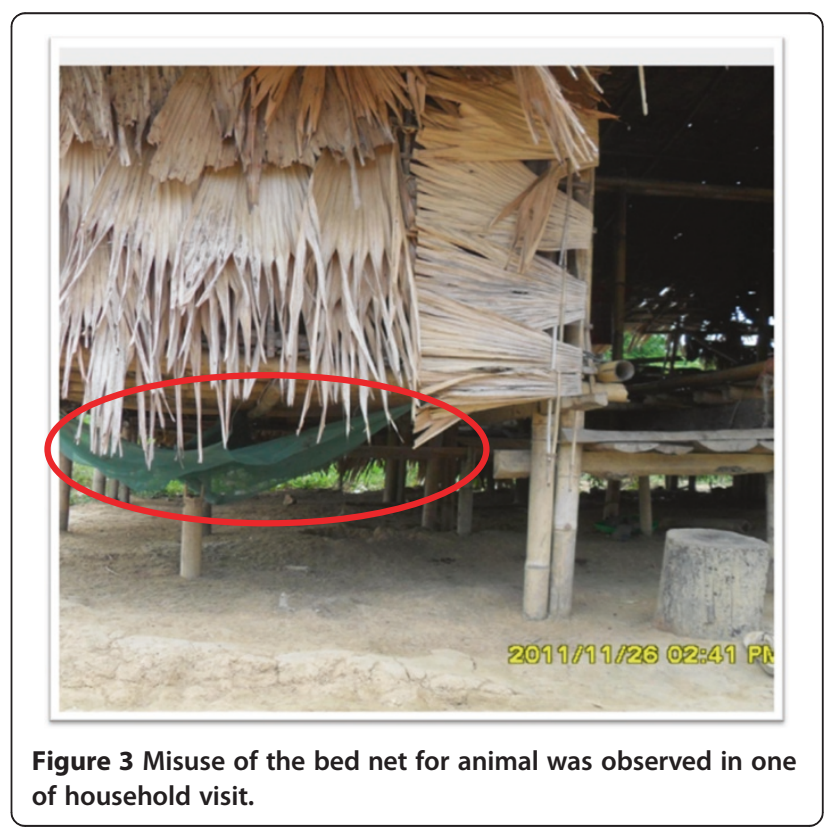


ing timely and sound evidence to guide implementation and inform policy decision-making are critical. There should be efforts to improve the effectiveness of ITN and/or behaviour change interventions to improve net longevity and usage with continuous mass free distribution, durability monitoring and insecticide resistance of the vector in target migrant plantation workers.

\section{Policy implications and recommendations}

- Net manufacturers and purchasers should be aware that the end users would like to receive more durable and reliable ITNs.

- Behaviour change communication and health promotion on effective utilization of the ITNs in target migrant population should be stressed.

- Integrated Vector Management should be emphasized, especially on the migrant employees who need to work at night.

- It is also recommended to monitor the efficacy and durability of the distributed ITNs and determine the factors responsible for reducing the efficacy of ITNs.

\section{Abbreviations}

ITNs: Insecticide treated bed nets; LLINs: Long lasting insecticidal nets; BCC: Behaviour change communication; MARC: Myanmar Artemisinin Resistance Containment; HHS: Household survey; FGD: Focus group discussion; NGO: Non-Governmental Organization; USD: United State Dollar.

\section{Competing interests}

The authors declare that they have no competing interests.

\section{Authors' contributions}

MHN, KMA, MPK, TH and TTK conceived and designed the study. MHN, KMA, NNZ, TTA and NAS conducted the field work. KMA, KO and MHN conducted statistical analysis, data validation and management. All authors contributed during writing, and read and approved the manuscript.

\section{Acknowledgements}

The authors would like to express their gratitude towards authorities from Department of Medical Research (lower Myanmar) and Department of Health for allowing us to conduct this study. The authors also like to thanks migrant plantation worker who actively participated in this study and staff from the Parasitology Research Division, Department of Medical Research (Lower Myanmar) for sample collection in the field. This study was supported by Joint SEARO-TDR Small Grants Programme (SEA-2011-T16-TSA-0008).

\footnotetext{
Author details

'Department of Medical Research (Lower Myanmar), Yangon, Republic of the Union of Myanmar. ${ }^{2}$ Department of Health, Naypyitaw, Republic of the Union of Myanmar. ${ }^{3}$ Department of Medical Research (Upper Myanmar), Pyin Oo Lwin, Republic of the Union of Myanmar.
}

Received: 23 March 2014 Accepted: 25 May 2014

Published: 2 June 2014

\section{References}

1. WHO: World Malaria Report 2008. Geneva: World Health Organization; 2009.

2. WHO: World Malaria Report 2010. Geneva: World Health Organization; 2011.

3. WHO: Insecticide-Treated Mosquito Nets: A WHO Position Statement. Geneva: World Health Organization; 2007.

4. WHO: World Malaria Report 2009. Geneva: World Health Organization; 2007.

5. Cohen J, Dupas P: Free distribution or cost-sharing? Evidence from a randomized malaria prevention experiment. Q J Econ 2010, 125:1-45.
6. Macintyre K, Keating J, Okbaldt YB, Zerom M, Sosler S, Ghe-bremeskel T, Eisele TP: Rolling out insecticide treated nets in Eritrea: examining the determinants of possession and use in malarious zones during the rainy season. Trop Med Int Health 2006, 11:824-233.

7. Githinji S, Herbst S, Kistemann T, Noor AM: Mosquito nets in a rural area of western kenya: ownership, use and quality. Malar J 2010, 9:250.

8. Ye Y, Patton E, Kilian A, Dovey S, Eckert E: Can universal insecticide-treated net campaigns achieve equity in coverage and use? The case of northern Nigeria. Malar J 2012, 11:32.

9. Ruhago GM, Mujinja PGM, Norheim OF: Equity implications of coverage and use of insecticide treated nets distributed for free or with copayment in two districts in Tanzania: a cross-sectional comparative household survey. Int J Equity Health 2011, 10:29.

10. Ministry of Health: Health in Myanmar 2013. Union of the Republic of Myanmar: Ministry of Health; 2013.

11. Lin K, Aung S, Lwin S, Min H, Aye NN, Webber R: Promotion of insecticidetreated mosquito nets in Myanmar. Southeast Asian J Trop Med Public Health 2000, 31:444-447.

12. Chanda E, Mukonka VM, Kamuliwo M, Macdonald MB, Haque U: Operational scale entomological intervention for malaria control: strategies, achievements and challenges in Zambia. Malar J 2000, 12:10

13. Roberts D, Curtis C, Tren R, Sharp B, Shiff C, Bate R: Malaria control and public health. Emerg Infect Dis 2004, 10:1170-1171.

14. Ministry of Health: Township Health Profile of Kawthaung and Thanbyuzayat. Naypyitaw: Township Health Department, Department of Health; 2011.

15. WHO: Report of the informal consultation on Myanmar Artemisinin Resistance Containment Frame Work. Nay Pyi Taw: Meeting Report; 2011.

16. Lwanga SK, Lerieshow S: Sample Size Determination in Health Studies a Practical Manual. Geneva, Switzerland: World Health Organization; 1991.

17. WHO: Malaria Indicator Survey. WHO Household Questionnaire. Maryland: Macro Calverton; 2005

18. Kleinschmidt I, Schwabe C, Shiva M, Sima V, Segura JL, Mabunda SJ, Coleman $\mathrm{M}$ : Combining indoor residual spraying and insecticide-treated net interventions. Am J Trop Med Hyg 2009, 81:519-524.

19. Korenromp EL, Miller J, Cibulskis RE, Kabir Cham M, Alnwick D, Dye C Monitoring mosquito net coverage for malaria control in Africa: possession vs. use by children under 5years. Trop Med Int Health 2003, 8:693-703.

20. Binka FN, Adongo P: Acceptability and use of insecticide impregnated bednets in northern Ghana. Trop Med Int Health 1997, 2:499-507.

21. Kuile FOT, Terlouw DJ, Phillips-Howard PA, Hawley WA, Friedman JF, Kolczak MS, Kariuki SK, Shi YP, Kwena AM, Vulule JM, Nahlen BL: Impact of permethrin-treated bed nets on malaria and all-cause morbidity in young children in an area of intense perennial malaria transmission in western Kenya: cross-sectional survey. Am J Trop Med Hyg 2003, 68(Suppl 4):100-107.

22. Minakawa N, Dida GO, Sonye GO, Futami K, Kaneko S: Unforeseen misuses of bed nets in fishing villages along Lake Victoria. Malar J 2008, 7:165.

23. Oresanya OB, Hoshen M, Sofola OT: Utilization of insecticide-treated nets by under-five children in Nigeria: Assessing progress towards the Abuja targets. Malar J 2008, 7:145.

24. Loha E, Tefera K, Lindtjørn B: Freely distributed bed-net use among Chano Mille residents, south Ethiopia: a longitudinal study. Malar J 2013, 12:23.

\section{doi:10.1186/1475-2875-13-211}

Cite this article as: Nyunt et al:: Challenges in universal coverage and utilization of insecticide-treated bed nets in migrant plantation workers in Myanmar. Malaria Journal 2014 13:211. 